\title{
Eficácia de Herbicidas Aplicados em Pós-Emergência na Cultura da Soja Convencional e Transgênica ${ }^{1}$
}

\author{
Efficacy of Herbicides Applied in Post emergence on Conventional and Transgenic Soybean
}

\author{
CORREAA, M.J.P. ${ }^{2}$ e ALVES, P.L.C.A. ${ }^{3}$
}

\begin{abstract}
RESUMO - Na cultura da soja é frequente o uso de herbicidas seletivos aplicados em pósemergência para o controle das plantas daninhas. Com o objetivo de avaliar a eficiência e a seletividade de herbicidas aplicados em pós-emergência, isolados e em misturas, para o controle de plantas daninhas e os efeitos sobre o crescimento e o desenvolvimento da soja convencional (M-SOY 8001) e transgênica (M-SOY 7908 RR), foram desenvolvidos dois experimentos em campo, nos anos agrícolas 2006/2007 e 2007/2008. Os tratamentos constaram dos herbicidas: lactofen $\left(168 \mathrm{~g} \mathrm{ha}^{-1}\right)$, glyphosate $\left(1.080 \mathrm{~g} \mathrm{ha}^{-1}\right)$, lactofen + chlorimuronethyl $\left(96+10 \mathrm{~g} \mathrm{ha}^{-1}\right)$, chlorimuron-ethyl + imazethapyr $\left(10+70 \mathrm{~g} \mathrm{ha}^{-1}\right)$, chlorimuron-ethyl + bentazon $\left(10+600 \mathrm{~g} \mathrm{ha}^{-1}\right)$, glyphosate + imazethapyr $\left(900+70 \mathrm{~g} \mathrm{ha}^{-1}\right)$, lactofen + chlorimuronethyl + imazethapyr $\left(96+10+70 \mathrm{~g} \mathrm{ha}^{-1}\right)$ e lactofen + chlorimuron-ethyl + imazethapyr haloxyfop-methyl $\left(96+10+70+60 \mathrm{~g} \mathrm{ha}^{-1}\right)$. Além disso, mantiveram-se duas testemunhas sem aplicação de herbicida (capinada e sem capina). O delineamento experimental utilizado foi em blocos ao acaso, com quatro repetições. O herbicida lactofen aplicado isoladamente e em mistura com chlorimuron-etyl, imazethapyr e haloxyfop-methyl provocou intoxicação inicial às plantas de soja, porém aos 27 dias após aplicação a cultura apresentava-se recuperada. No primeiro ano agricola, as plantas daninhas foram satisfatoriamente controladas pelos tratamentos químicos. No segundo ano, os tratamentos que resultaram em melhor controle das infestantes foram glyphosate e glyphosate + imazethapyr. Houve redução na altura final das plantas, no segundo ano, tratadas com chlorimuron-ethyl + imazethapyr, lactofen + chlorimuron-ethyl + imazethapyr e lactofen + chlorimuron-ethyl + imazethapyr/haloxyfopmethyl. Foi constatada redução na produtividade de grãos da variedade M-SOY 7908 RR tratada com lactofen e com a mistura chlorimuron ethyl + bentazon no primeiro ano. A aplicação de chlorimuron-ethyl + bentazon proporcionou redução na produtividade da variedade M-SOY 8001 no segundo ano.
\end{abstract}

Palavras-chave: lactofen, fitotoxicidade, Glycine max, glyphosate.

\begin{abstract}
The use of selective herbicides is frequent in post emergence of soybean crop for weed control. A field experiment was conducted at the Education, Research and Production Farm of UNESP in Jaboticabal, SP, Brazil, during the growing years 2006/2007 and 2007/2008 to evaluate the efficiency and selectivity of post herbicide application, alone and in mixtures, for weed control, on conventional (M-SOY 8001) and transgenic (M-SOY 7908 RR) soybean growth and development. Treatments consisted of the application of the following herbicides, alone or in mixture: lactofen (168 $\left.\mathrm{g} \mathrm{ha}^{-1}\right)$, glyphosate (1080 $\left.\mathrm{g} \mathrm{ha}^{-1}\right)$, lactofen + chlorimuron-ethyl $\left(96+10 \mathrm{gha}^{-1}\right)$, chlorimuron-ethyl + imazethapyr $\left(10+70 \mathrm{~g} \mathrm{ha}^{-1}\right)$, chlorimuron-ethyl + bentazon $\left(10+600 \mathrm{~g} \mathrm{ha} \mathrm{h}^{-1}\right)$, glyphosate + imazethapyr $\left(900+70 \mathrm{~g} \mathrm{ha}^{-1}\right)$, lactofen + chlorimuron-ethyl + imazethapyr $\left(96+10+70 \mathrm{~g} \mathrm{ha}^{-1}\right)$ and lactofen + chlorimuron-ethyl + imazethapyr/haloxyfop-methyl $\left(96+10+70+60 \mathrm{~g} \mathrm{ha} \mathrm{H}^{-1}\right)$. The tests included two non-treated controls. A randomized block experimental design was used with four replications. Lactofen applied alone and the mixtures chlorimuron-etyl, imazethapyr and haloxyfopmethyl did not cause initial injury in the soybean plants, but the plants recovered on the $27^{\text {th }}$ day
\end{abstract}

Recebido para publicação em 14.11.2008 e na forma revisada em 11.12.2009

2 Professora Adjunta, Drª ., Dep. de Química e Biologia, Universidade Estadual do Maranhão - UEMA. Campus Universitário Paulo VI, s/n. Tirirical, Caixa Postal 09, 65055-310 São Luís-MA, <mjcorreazea@hotmail.com>; ${ }^{3}$ Professor Assistente, Dr., Dep. de Biologia Aplicada à Agropecuária, FCAV/UNESP, Via de acesso Prof. Paulo Donato Castellane, s/n, 14884-900 Jaboticabal-SP, <plalves@fcav.unesp.br>. 
after application. In the first year, the chemical treatments did exert sufficient control overthe weeds and in the second year, the glyphosate and glyphosate + imazethapyrtreatments presented the best weed control. In the second year, a reduction was observed in the final height of the soybean plants treated with chlorimuron-ethyl + imazethapyr, lactofen + chlorimuron-ethyl + imazethapyr and lactofen + chlorimuron-ethyl + imazethapyr/haloxyfop-methyl. A yield reduction was verified in soybean M-SOY 7908 RR, treated with lactofen alone and with the mixture chlorimuron ethyl + bentazon in the first year. The chlorimuron-ethyl + bentazon treatment provided a reduction in soybean $M-S O Y 8001$ yield in the second year.

Keywords: lactofen, phytotoxicity, Glycine max, glyphosate.

\section{INTRODUÇÃO}

As plantas daninhas constituem um dos principais componentes bióticos do agroecossistema da soja e, quando não manejadas, afetam negativamente o desenvolvimento da cultura, geralmente causando redução na produtividade de grãos (Lamego et al., 2004). Além disso, competem com a cultura pelos recursos do meio, principalmente água, luz e nutrientes, liberando substâncias alelopáticas prejudiciais, atuando como hospedeiras de pragas e doenças comuns à cultura e interferindo nas práticas de colheita (Pitelli, 1985).

Devido à importância da cultura, existe a necessidade constante de pesquisas para aumentar a eficiência na produção, visando o aumento na competitividade do país internacionalmente (Constantin et al., 2000).

Com o aumento da área plantada em $3,1 \%$ com soja no Brasil na safra 2007/2008 (CONAB, 2008) e a adoção das tecnologias disponíveis, a utilização de herbicidas em pós-emergência tem se tornado cada vez mais frequente (Petter et al., 2007). No entanto, o uso constante de um herbicida ou de herbicidas com o mesmo mecanismo de ação exerce alta pressão de seleção, o que reduz ou elimina indivíduos suscetiveis e, em contrapartida, aumenta o número de indivíduos tolerantes e a manifestação de biótipos resistentes, que, provavelmente, já existiam na população, mas em frequência bastante baixa (Christoffoleti et al., 1994).

Nesse contexto, a mistura de herbicidas está se tornando uma prática muito utilizada no controle de plantas daninhas, uma vez que estas têm demonstrado aumento do número de espécies controladas dentro do complexo florístico infestante. Além disso, é considerada uma prática benéfica na prevenção do aparecimento de plantas daninhas resistentes a herbicidas (Vargas et al., 1999). Segundo Constantin et al. (2000), os herbicidas bentazon, chlorimuron-ethyl, lactofen e imazethapyr são muito utilizados no controle de dicotiledôneas em pós-emergência na cultura da soja, isolados ou em mistura em tanque entre si.

No entanto, são necessárias as informações relativas à seletividade desses produtos químicos à cultura. Souza et al. (2002), trabalhando com diferentes doses do herbicida lactofen na cultura da soja, observaram que a fitointoxicação provocada pelo lactofen isolado atingiu valores intermediários da escala EWRC no terceiro dia após a aplicação, mas, com o desenvolvimento da cultura, os sintomas se tornaram menos intensos até o décimo dia após a aplicação e, a partir do vigésimo dia, desapareceram completamente.

Em outro trabalho, Melhorança \& Pereira (2000) verificaram que o lactofen isolado (120 $\mathrm{g} \mathrm{ha}^{-1}$ ) ou em mistura com imazethapyr, aos sete dias após a aplicação do tratamento (DAT), ocasionou as maiores injúrias visuais na soja. Contudo, aos 14 DAT houve sensivel redução dos sintomas e, aos 30 DAT, constatou-se ausência de fitotoxicidade em todos os tratamentos aplicados.

Com a liberação do cultivo de soja transgênica no Brasil, a intensidade do uso do herbicida glyphosate na cultura, que já era grande devido às aplicações de dessecação de manejo, passou a ser ainda maior, com a possibilidade de realizar aplicações em pós-emergência sobre as plantas de soja geneticamente modificadas (Petter et al., 2007). Entretato, alguns 
resultados de pesquisa têm demonstrado que o uso de glyphosate combinado com herbicidas aplicados em soja convencional aumenta o espectro e a eficácia de controle de plantas consideradas mais tolerantes à ação do glyphosate isolado (Monquero et al., 2001; Vidrine et al., 2002; Procópio et al., 2007).

Em vista da introdução de cultivares transgênicos e da necessidade de utilizar misturas de herbicidas para aumentar o espectro e a eficiência de controle das plantas daninhas, torna-se primordial conhecer, também, os efeitos deletérios dessas misturas nas culturas. Dessa forma, o presente trabalho teve por objetivo avaliar a eficácia e seletividade de herbicidas aplicados em pós-emergência, isolados e em misturas, no controle de plantas daninhas, bem como os efeitos sobre o crescimento e o desenvolvimento da soja convencional e transgênica.

\section{MATERIAL E MÉTODOS}

O experimento foi desenvolvido em campo, nos anos agrícolas 2006/2007 e 2007/2008, em duas áreas experimentais da Fazenda de Ensino, Pesquisa e Produção pertencente à Faculdade de Ciências Agrárias e Veterinárias da Universidade Estadual Paulista UNESP, localizada no município de Jaboticabal - SP, que se encontra em latitude de $21^{\circ} 15^{\prime} 22^{\prime \prime} \mathrm{S}$, longitude de $48^{\circ} 18^{\prime} 58^{\prime} \mathrm{W}$ e altitude de $595 \mathrm{~m}$.

O solo da área experimental do primeiro ano agrícola é classificado como Latossolo Vermelho eutroférrico típico textura muito argilosa A moderado e relevo suave ondulado, e o do segundo, como Latossolo Vermelho eutrófico típico textura argilosa A moderado e relevo suave ondulado (Andrioli \& Centurion, 1999). O preparo do solo consistiu de aração e gradagem.

A semeadura da soja transgênica (M-SOY $7908 \mathrm{RR})$ e convencional (M-SOY 8001) foi realizada em 8 de dezembro de 2006 e 15 de dezembro de 2007, no primeiro e segundo anos, respectivamente. Os cultivares de soja foram semeados no espaçamento de $0,45 \mathrm{~m}$ entre linhas, depositando-se 21 e 18 sementes por metro, sendo utilizados $300 \mathrm{~kg} \mathrm{ha}^{-1}$ de 0-20-20 e $300 \mathrm{~kg} \mathrm{ha}^{-1}$ de 8-20-20 no sulco de semeadura, no primeiro e segundo anos, respectivamente. Antes da semeadura, procedeu-se ao tratamento das sementes com Thiram (300 mL $100 \mathrm{~kg}^{-1}$ de sementes). Em seguida, as sementes foram inoculadas com $2 \mathrm{~g}$ de Masterfix por $\mathrm{kg}$ de semente.

A soja transgênica (M-SOY 7908 RR) é de ciclo precoce, altura média de $70 \mathrm{~cm}$, crescimento determinado, moderadamente resistente ao Meloydogine javanica e suscetivel ao Meloydogine incognita e Heterodera glycines. A M-SOY 8001 apresenta ciclo semiprecoce, crescimento determinado e é resistente a Heterodera glycines, tolerante a Meloydogine javanica e suscetivel a Meloydogine incognita (CAROL, 2007).

Os tratamentos foram constituídos da aplicação de herbicidas isolados e em mistura, e as testemunhas (capinada e sem capina) não receberam aplicação de herbicida (Tabela 1). $\mathrm{O}$ delineamento experimental foi em blocos casualizados, com dez tratamentos e quatro repetições. As parcelas experimentais apresentaram sete linhas de semeadura, espaçadas de 0,45 m entre linhas, com $5 \mathrm{~m}$ de comprimento cada, resultando numa área de $15,75 \mathrm{~m}^{2}(3,15 \times 5 \mathrm{~m})$, considerando como área útil as três linhas centrais, perfazendo $6,75 \mathrm{~m}^{2}(1,35 \times 5 \mathrm{~m})$ de área.

Os herbicidas foram aplicados quando as plantas de soja se encontravam com o quinto ou sexto (estádios V6 e V7) e quarto ou quinto (estádios V5 e V6) trifólios totalmente expandidos, segundo escala fenológica proposta por Ritchie et al. (1977), no primeiro e segundo anos, respectivamente. O herbicida haloxifopmethyl foi aplicado em seguida à pulverização da mistura lactofen + chlorimuron-ethyl + imazethapyr, para que sua absorção não fosse prejudicada. Foi utilizado pulverizador costal, à pressão constante (mantida pelo $\mathrm{CO}_{2}$ comprimido) de 2,24 $\mathrm{kgf} \mathrm{cm}^{-2}$, munido de barra com seis pontas de pulverização 110.02 , espaçadas de $0,5 \mathrm{~m}$, com consumo de calda equivalente a $200 \mathrm{~L} \mathrm{ha}^{-1}$. No momento da aplicação foram registrados, para o primeiro e segundo anos, respectivamente, $34^{\circ} \mathrm{C}$ e $33^{\circ} \mathrm{C}$ de temperatura do ar; $28{ }^{\circ} \mathrm{C}$ e $31^{\circ} \mathrm{C}$ de temperatura do solo; 72 e $52 \%$ de umidade relativa do ar; ventos leves com velocidade de $2,0 \mathrm{~km} \mathrm{~h}^{-1}$; e nebulosidade em torno de 80 e $30 \%$. 
Tabela 1 - Tratamentos e doses dos herbicidas utilizados nos anos agrícolas 2006/2007 e 2007/2008. Jaboticabal-SP, 2008

\begin{tabular}{|c|c|}
\hline \multirow[b]{2}{*}{ Nome comum } & Dose \\
\hline & $\begin{array}{l}\text { i.a. }{ }^{-1 /} \text { ou e. } \mathrm{a}^{2 /}{ }^{\prime \prime} \\
\left(\mathrm{g} \mathrm{ha}^{-1}\right)\end{array}$ \\
\hline 1 - testemunha sem capina & - \\
\hline 2 - testemunha capinada & - \\
\hline 3 - lactofen & 168 \\
\hline 4 - glyphosate & 1.080 \\
\hline 5 - lactofen + chlorimuron-ethyl & $96+10$ \\
\hline 6 - chlorimuron-ethyl + imazethapyr & $10+70$ \\
\hline 7 - chlorimuron-ethyl + bentazon & $10+600$ \\
\hline 8 - glyphosate + imazethapyr & $900+70$ \\
\hline $\begin{array}{l}9 \text { - lactofen }+ \text { chlorimuron-ethyl }+ \\
\text { imazethapyr }\end{array}$ & $96+10+70$ \\
\hline $\begin{array}{l}10 \text { - lactofen }+ \text { chlorimuron -ethyl }+ \\
\text { imazethapyr/haloxyfop-methyl }\end{array}$ & $96+10+70+60$ \\
\hline
\end{tabular}

No decorrer do período experimental, foram realizadas aplicações de inseticidas e fungicidas, visando principalmente o controle de lagartas, percevejos e da ferrugem-asiática, fazendo-se as pulverizações sempre que necessário.

As avaliações visuais de intoxicação na soja foram feitas aos 6,13,20, 27 e 37 dias após a aplicação (DAA) dos herbicidas, atribuindo-se a cada unidade experimental uma nota, utilizando-se a escala de valores proposta pela European Weed Research Council (EWRC, 1964), em que 1 = nenhuma injúria e $9=$ morte da planta. Nas mesmas épocas e na pré-colheita foram feitas as avaliações de controle, por meio de escala visual de O a 100\% (ausência de controle e controle total das plantas daninhas, respectivamente), cuja nota foi atribuída à comunidade infestante em geral na parcela.

Na pré-colheita (estádio R9), foram realizadas as avaliações da massa seca das plantas daninhas e dos componentes de produção da soja. $\mathrm{Na}$ área onde foi instalado o experimento, no primeiro ano, havia baixa infestação de plantas daninhas, comparada à área no segundo ano, com alta infestação de plantas. A avaliação da massa seca da comunidade infestante foi feita com o lançamento aleatório de quadrado metálico de $0,25 \mathrm{~m}^{2}$ de área, por duas vezes, na área útil de cada parcela. As plantas daninhas foram coletadas e acondicionadas em sacos de papel, que foram levados à estufa com ventilação forçada de ar a $70^{\circ} \mathrm{C}$ por 72 horas. Para determinação da altura final de plantas, altura de inserção da primeira vagem e número de vagens por planta, foram coletadas dez plantas em linha, na sequência por parcela. Quanto à altura final de planta, mediu-se a distância compreendida entre o colo da planta e o ápice da haste principal; para altura de inserção da primeira vagem, considerou-se a distância entre o colo da planta e o ponto de inserção da primeira vagem.

A colheita da soja foi realizada em 10 de abril de 2007 e 24 de abril de 2008. Para obtenção da produção de grãos, foram colhidas três linhas centrais de $5 \mathrm{~m}$ de comprimento em cada parcela, sendo posteriormente corrigida a umidade dos grãos para 13\%. Determinou-se também a massa de 100 grãos.

Os resultados obtidos foram submetidos ao teste $\mathrm{F}$ para análise de variância, e as médias, comparadas pelo teste de Tukey a $5 \%$ de probabilidade. Os dados obtidos para número de vagens e porcentagem de controle de plantas daninhas foram previamente transformados em $V_{\mathrm{x}}$ e Arc sen $V_{\mathrm{x}}$, respectivamente.

\section{RESULTADOS E DISCUSSÃO}

\section{Fitotoxicidade}

No primeiro e segundo anos, os sintomas de intoxicação visual foram observados nas folhas de soja das duas variedades para lactofen isolado, lactofen + chlorimuron-ethyl, lactofen + chlorimuron-ethyl + imazethapyr e lactofen + chlorimuron-ethyl + imazethapyr/haloxyfopmethyl, com valores intermediários da escala EWRC aos 6 DAA (Tabelas 2 e 3), provocando sintomas visuais como clorose, bronzeamento e necrose das folhas, em especial nas margens, acompanhadas de deformação (enrugamento) em folhas e brotos. Aos 13 DAA, os danos visuais apresentaram-se menos intensos, desaparecendo gradativamente até os 20 DAA. No entanto, a gema apical não foi afetada, pois os sintomas de intoxicação desapareceram com o desenvolvimento das plantas, devido à emissão e expansão de folhas novas.

Souza et al. (2002) obtiveram resultados semelhantes trabalhando com diferentes doses do herbicida lactofen na cultura da soja. 
Esses autores observaram que a fitointoxicação provocada pelo lactofen isolado atingiu valores intermediários da escala EWRC no terceiro dia após a aplicação, porém, com o desenvolvimento da cultura, os sintomas se tornaram menos intensos até o décimo dia após a aplicação e, a partir do vigésimo dia, desapareceram completamente. Ainda nesse contexto, o mesmo foi observado por Wichert \& Talbert (1993) aos 8 DAA com aplicação de lactofen nas doses de $220 \mathrm{e} 440 \mathrm{~g}$ ha ${ }^{1}$.

Foloni et al. (2005) constataram intoxicação de leve a moderada na cultura da soja transgênica até 20 dias após a aplicação da combinação dos herbicidas lactofen +

Tabela 2 - Fitotoxicidade estimada nas variedades de soja M-SOY 7908 RR e M-SOY 8001 em relação aos dias após a aplicação dos tratamentos (DAA) no ano agrícola 2006/ 2007. Jaboticabal-SP, 2008

\begin{tabular}{|l|c|c|c|c|c|}
\hline Tratamento & 6 DAA & 13 DAA & 20 DAA & 27 DAA & 37 DAA \\
\hline \multicolumn{7}{|c|}{ M-SOY 7908 RR } \\
\hline T1 & $1,0 \mathrm{c}$ & $1,0 \mathrm{~d}$ & $1,0 \mathrm{c}$ & 1,0 & 1,0 \\
\hline T2 & $1,0 \mathrm{c}$ & $1,0 \mathrm{~d}$ & $1,0 \mathrm{c}$ & 1,0 & 1,0 \\
\hline T3 & $6,0 \mathrm{a}$ & $4,2 \mathrm{a}$ & $3,2 \mathrm{a}$ & 2,0 & 1,0 \\
\hline T4 & $1,0 \mathrm{c}$ & $1,0 \mathrm{~d}$ & $1,0 \mathrm{c}$ & 1,0 & 1,0 \\
\hline T5 & $4,0 \mathrm{~b}$ & $2,2 \mathrm{bc}$ & $2 \mathrm{bc}$ & 1,0 & 1,0 \\
\hline T6 & $1,7 \mathrm{c}$ & $1,5 \mathrm{~cd}$ & $1,5 \mathrm{bc}$ & 1,0 & 1,0 \\
\hline T7 & $1,2 \mathrm{c}$ & $1,7 \mathrm{bcd}$ & $1,2 \mathrm{c}$ & 1,0 & 1,0 \\
T8 & $1,0 \mathrm{c}$ & $2,0 \mathrm{bcd}$ & $1,0 \mathrm{c}$ & 1,0 & 1,0 \\
\hline T9 & $4,0 \mathrm{~b}$ & $2,7 \mathrm{~b}$ & $3,2 \mathrm{a}$ & 1,0 & 1,0 \\
\hline T10 & $4,0 \mathrm{~b}$ & $2,5 \mathrm{bc}$ & $2,5 \mathrm{ab}$ & 1,0 & 1,0 \\
\hline F (trat) & $53,6 * *$ & $14,0^{* *}$ & $14,0^{* *}$ & $2,0 \mathrm{~ns}$ & $0,7^{\mathrm{ns}}$ \\
CV (\%) & 19,6 & 24,7 & 27,8 & 40,6 & 26,4 \\
DMS (Tukey) & 1,2 & 1,2 & 1,2 & 1,1 & 0,7 \\
\hline \multicolumn{7}{|c|}{ M-SOY 8001} & \\
\hline T1 & $1,0 \mathrm{~d}$ & $1,0 \mathrm{e}$ & $1,0 \mathrm{c}$ & $1,0 \mathrm{~b}$ & $1,0 \mathrm{~b}$ \\
\hline T2 & $1,0 \mathrm{~d}$ & $1,0 \mathrm{e}$ & $1,0 \mathrm{c}$ & $1,0 \mathrm{~b}$ & $1,0 \mathrm{~b}$ \\
\hline T3 & $5,0 \mathrm{~b}$ & $3,0 \mathrm{~b}$ & $2,0 \mathrm{~b}$ & $1,0 \mathrm{~b}$ & $1,0 \mathrm{~b}$ \\
\hline T4 & $9,0 \mathrm{a}$ & $9,0 \mathrm{a}$ & $9,0 \mathrm{a}$ & $9,0 \mathrm{a}$ & $9,0 \mathrm{a}$ \\
\hline T5 & $4,3 \mathrm{~b}$ & $2,2 \mathrm{bcd}$ & $1,0 \mathrm{c}$ & $1,0 \mathrm{~b}$ & $1,0 \mathrm{~b}$ \\
\hline T6 & $2,7 \mathrm{c}$ & $1,7 \mathrm{cde}$ & $1,2 \mathrm{bc}$ & $1,0 \mathrm{~b}$ & $1,0 \mathrm{~b}$ \\
\hline T7 & $1,5 \mathrm{~cd}$ & $1,2 \mathrm{de}$ & $1,0 \mathrm{c}$ & $1,0 \mathrm{~b}$ & $1,0 \mathrm{~b}$ \\
\hline T8 & $9,0 \mathrm{a}$ & $9,0 \mathrm{a}$ & $9,0 \mathrm{a}$ & $9,0 \mathrm{a}$ & $9,0 \mathrm{a}$ \\
\hline T9 & $4,7 \mathrm{~b}$ & $2,2 \mathrm{bcd}$ & $1,2 \mathrm{bc}$ & $1,0 \mathrm{~b}$ & $1,0 \mathrm{~b}$ \\
\hline T10 & $4,3 \mathrm{~b}$ & $2,5 \mathrm{bc}$ & $1,5 \mathrm{bc}$ & $1,0 \mathrm{~b}$ & $1,0 \mathrm{~b}$ \\
\hline F (trat) & $103 * *$ & $154^{* *}$ & $271^{* *}$ & $74050^{* *}$ & $74050^{* *}$ \\
CV (\%) & 13,5 & 14,9 & 14,2 & 0,9 & 0,9 \\
DMS (Tukey) & 1,3 & 1,2 & 0,9 & 0,1 & 0,1 \\
\hline
\end{tabular}

T1 - testemunha sem capina; T2 - testemunha capinada; T3 lactofen; T4 - glyphosate; T5 - lactofen + chlorimuron-ethyl; T6 - chlorimuron-ethyl + imazethapyr; T7 - chlorimuron-ethyl + bentazon; T8 - glyphosate + imazethapyr; T9 - lactofen + chlorimuron-ethyl + imazethapyr; T10 - lactofen + chlorimuronethyl + imazethapyr/haloxyfop-methyl.

Médias seguidas da mesma letra na coluna não diferem significativamente entre si pelo teste de Tukey a $5 \%$ de probabilidade. chlorimuron-ethyl, o que não corresponde aos dados encontrados neste trabalho, no qual aos 20 DAA a intoxicação foi considerada muito leve a nula (sem dano às plantas).

Em relação à aplicação de glyphosate isolado nos dois anos de estudo e glyphosate em mistura ao imazethapyr no primeiro ano, não foram observados sintomas de intoxicação na variedade transgênica. Esses dados corroboram os encontrados por Procópio et al. (2007), ao constatarem que a aplicação isolada de glyphosate não ocasionou sintomas de intoxicação nas plantas da soja transgênica M-SOY 7878. Entretanto, Foloni et al. (2005) constataram leve intoxicação na variedade

Tabela 3 - Fitotoxicidade estimada nas variedades de soja M-SOY 7908 RR e M-SOY 8001 em relação aos dias após a aplicação dos tratamentos no ano agrícola 2007/2008. Jaboticabal-SP, 2008

\begin{tabular}{|l|c|c|c|c|c|}
\hline Tratamento & 6 DAA & 13 DAA & 20 DAA & 27 DAA & 37 DAA \\
\hline \multicolumn{7}{|c|}{ M-SOY 7908 RR } \\
\hline T1 & $1,0 \mathrm{~d}$ & $1,0 \mathrm{c}$ & $1,0 \mathrm{c}$ & 1,0 & 1,0 \\
\hline T2 & $1,0 \mathrm{~d}$ & $1,0 \mathrm{c}$ & $1,0 \mathrm{c}$ & 1,0 & 1,0 \\
\hline T3 & $6,0 \mathrm{a}$ & $3,5 \mathrm{ab}$ & $1,3 \mathrm{bc}$ & 1,0 & 1,0 \\
\hline T4 & $1,0 \mathrm{~d}$ & $1,0 \mathrm{c}$ & $1,0 \mathrm{c}$ & 1,0 & 1,0 \\
\hline T5 & $4,3 \mathrm{~b}$ & $2,5 \mathrm{bc}$ & $1,0 \mathrm{c}$ & 1,0 & 1,0 \\
\hline T6 & $4,3 \mathrm{~b}$ & $5,0 \mathrm{a}$ & $2,0 \mathrm{a}$ & 1,8 & 1,8 \\
\hline T7 & $1,0 \mathrm{~d}$ & $1,5 \mathrm{c}$ & $1,0 \mathrm{c}$ & 1,0 & 1,0 \\
\hline T8 & $2,8 \mathrm{~d}$ & $2,0 \mathrm{bc}$ & $1,0 \mathrm{c}$ & 1,0 & 1,0 \\
\hline T9 & $5,5 \mathrm{ab}$ & $3,5 \mathrm{ab}$ & $1,3 \mathrm{bc}$ & 1,5 & 1,5 \\
\hline T10 & $5,3 \mathrm{ab}$ & $3,7 \mathrm{ab}$ & $1,8 \mathrm{ab}$ & 1,0 & 1,25 \\
\hline F (trat) & $54,5^{* *}$ & $13,9^{* *}$ & $7,1^{* *}$ & $2,2^{*}$ & $2,2^{*}$ \\
CV (\%) & 17,6 & 30,3 & 22,0 & 28,6 & 28,6 \\
DMS (Tukey) & 1,3 & 1,8 & 0,6 & 0,8 & 0,8 \\
\hline \multicolumn{7}{|c|}{ M-SOY 8001} & \\
\hline T1 & $1,0 \mathrm{~d}$ & $1,0 \mathrm{~d}$ & $1,0 \mathrm{c}$ & $1,0 \mathrm{~d}$ & $1,0 \mathrm{c}$ \\
\hline T2 & $1,0 \mathrm{~d}$ & $1,0 \mathrm{~d}$ & $1,0 \mathrm{c}$ & $1,0 \mathrm{~d}$ & $1,0 \mathrm{c}$ \\
\hline T3 & $4,7 \mathrm{~b}$ & $2,7 \mathrm{bc}$ & $1,7 \mathrm{bc}$ & $1,0 \mathrm{~d}$ & $1,0 \mathrm{c}$ \\
\hline T4 & $9,0 \mathrm{a}$ & $9,0 \mathrm{a}$ & $9,0 \mathrm{a}$ & $9,0 \mathrm{a}$ & $9,0 \mathrm{a}$ \\
\hline T5 & $3,5 \mathrm{c}$ & $2,7 \mathrm{bc}$ & $2,0 \mathrm{~b}$ & $1,2 \mathrm{~cd}$ & $1,2 \mathrm{c}$ \\
\hline T6 & $4,2 \mathrm{bc}$ & $3,2 \mathrm{~b}$ & $2,2 \mathrm{~b}$ & $2,0 \mathrm{bc}$ & $1,7 \mathrm{bc}$ \\
\hline T7 & $1,2 \mathrm{~d}$ & $1,5 \mathrm{~cd}$ & $1,0 \mathrm{c}$ & $1,0 \mathrm{~d}$ & $1,0 \mathrm{c}$ \\
\hline T8 & $9,0 \mathrm{a}$ & $9,0 \mathrm{a}$ & $9,0 \mathrm{a}$ & $9,0 \mathrm{a}$ & $9,0 \mathrm{a}$ \\
\hline T9 & $4,2 \mathrm{bc}$ & $3,5 \mathrm{~b}$ & $1,7 \mathrm{bc}$ & $1,2 \mathrm{~cd}$ & $1,5 \mathrm{bc}$ \\
\hline T10 & $4,2 \mathrm{bc}$ & $3,2 \mathrm{~b}$ & $2,0 \mathrm{~b}$ & $2,2 \mathrm{~b}$ & $2,2 \mathrm{bc}$ \\
\hline F (trat) & $145,4^{* *}$ & $89,8^{* *}$ & $284,9^{* *}$ & $339,6^{* *}$ & $261,3 * *$ \\
CV (\%) & 11,4 & 16,7 & 12,1 & 12,3 & 14,0 \\
DMS (Tukey) & 1,1 & 1,5 & 0,9 & 0,8 & 0,9 \\
\hline
\end{tabular}

T1 - testemunha sem capina; T2 - testemunha capinada; T3 lactofen; T4 - glyphosate; T5 - lactofen + chlorimuron-ethyl; T6 - chlorimuron-ethyl + imazethapyr; T7 - chlorimuron-ethyl + bentazon; T8 - glyphosate + imazethapyr; T9 - lactofen + chlorimuron-ethyl + imazethapyr; T10 - lactofen + chlorimuronethyl + imazethapyr/haloxyfop-methyl.

Médias seguidas da mesma letra na coluna não diferem significativamente entre si pelo teste de Tukey a $5 \%$ de probabilidade. 
transgênica M-SOY 8888 após a aplicação isolada de glyphosate. Segundo Krausz \& Young (2001a), o glyphosate causou clorose mais acentuada nas folhas quando aplicado no estádio R1 da soja, e isso foi intensificado com o aumento das doses utilizadas. No presente trabalho, as plantas de soja da variedade M-SOY 8001 tratadas com glyphosate isolado e glyphosate + imazethapyr morreram.

As plantas dos dois cultivares tratadas com chlorimuron-ethyl + imazethapyr no primeiro ano e chlorimuron-ethyl + bentazon no primeiro e segundo anos apresentaram injúrias visuais muito leves.

A partir dos 27 DAA, os sintomas de fitointoxicação ocasionados pela aplicação dos herbicidas foram muito leves a nulos em todos os tratamentos, independentemente do cultivar, exceto para o herbicida glyphosate isoladamente e em mistura ao imazethapyr aplicados à variedade convencional, não tolerante ao glyphosate.

No segundo ano agrícola, a mistura glyphosate + imazethapyr causou injúrias visuais às plantas do cultivar transgênico, atingindo níveis da escala EWRC de leve a muito leve aos 6 e 13 DAA. Em trabalho realizado por Procópio et al. (2007), a adição de $100 \mathrm{~g} \mathrm{ha}^{-1}$ de imazethapyr ao glyphosate nas doses de 480, 960 ou $1.440 \mathrm{~g} \mathrm{ha}^{-1}$ acarretou níveis de intoxicação de $33 \%$ às plantas de soja aos 13 DAA, similar ao observado neste estudo.

A fitointoxicação ocasionada pela mistura chlorimuron-ethyl + imazethapyr (Tabela 3) nos dois cultivares atingiu niveis de regular a leve na escala EWRC aos 6 e 13 DAA, respectivamente. Os sintomas evidenciados foram murcha das folhas, clorose no local onde o produto foi depositado e redução na altura das plantas quando comparada à das testemunhas. No entanto, com o desenvolvimento das plantas, os sintomas foram desaparecendo completamente.

\section{Controle das plantas daninhas}

Nas avaliações de controle das plantas daninhas na pré-colheita da soja (estádio de desenvolvimento da cultura R9), as principais plantas daninhas presentes na área experimental do primeiro ano foram:
Alternanthera tenella (apaga-fogo), Digitaria nuda (capim-colchão), Cenchrus echinatus (capim-carrapicho), Eleusine indica (capim-pé-de-galinha), Acanthospermum hispidum (carrapicho-decarneiro) e Amaranthus deflexus, com $51 \%$ de plantas daninhas monocotiledôneas e 49\% de dicotiledôneas e predominância de apaga-fogo e capim-colchão.

Para a soja M-SOY 7908 RR, os tratamentos glyphosate, chlorimuron-ethyl + imazethapyr, glyphosate + imazethapyr, lactofen + chlorimuron-ethyl + imazethapyr e lactofen + chlorimuron-ethyl + imazethapyr/ haloxyfop-methyl proporcionaram controle das plantas daninhas semelhante ao da testemunha capinada, dos 6 aos 37 DAA (Tabela 4).

Tabela 4 - Nível de controle (\%) de plantas daninhas estimado nas variedades de soja M-SOY 7908 RR e M-SOY $8001 \mathrm{em}$ relação aos dias após a aplicação dos tratamentos no ano agrícola 2006/2007. Jaboticabal-SP, 2008

\begin{tabular}{|l|c|c|c|c|c|c|}
\hline Tratamento & 6 DAA & 13 DAA & 20 DAA & 27 DAA & 37 DAA & $\begin{array}{c}\text { Pré- } \\
\text { colheita }\end{array}$ \\
\hline \multicolumn{7}{|c|}{ M-SOY 7908 RR } \\
\hline T1 & $0 \mathrm{c}$ & $0 \mathrm{c}$ & $0 \mathrm{e}$ & $0 \mathrm{c}$ & $0 \mathrm{~d}$ & $0 \mathrm{~d}$ \\
\hline T2 & $90 \mathrm{a}$ & $90 \mathrm{a}$ & $90 \mathrm{a}$ & $90 \mathrm{a}$ & $90 \mathrm{a}$ & $90 \mathrm{a}$ \\
\hline T3 & $68 \mathrm{~b}$ & $68 \mathrm{~b}$ & $70 \mathrm{~d}$ & $70 \mathrm{~b}$ & $70 \mathrm{c}$ & $68 \mathrm{bc}$ \\
\hline T4 & $90 \mathrm{a}$ & $90 \mathrm{a}$ & $90 \mathrm{a}$ & $90 \mathrm{a}$ & $90 \mathrm{a}$ & $90 \mathrm{a}$ \\
\hline T5 & $69 \mathrm{~b}$ & $69 \mathrm{~b}$ & $73 \mathrm{~cd}$ & $73 \mathrm{~b}$ & $73 \mathrm{bc}$ & $64 \mathrm{c}$ \\
\hline T6 & $84 \mathrm{a}$ & $84 \mathrm{a}$ & $84 \mathrm{abc}$ & $80 \mathrm{ab}$ & $80 \mathrm{abc}$ & $65 \mathrm{c}$ \\
\hline T7 & $68 \mathrm{~b}$ & $68 \mathrm{~b}$ & $75 \mathrm{bcd}$ & $68 \mathrm{~b}$ & $75 \mathrm{bc}$ & $69 \mathrm{bc}$ \\
\hline T8 & $90 \mathrm{a}$ & $90 \mathrm{a}$ & $90 \mathrm{a}$ & $90 \mathrm{a}$ & $90 \mathrm{a}$ & $90 \mathrm{a}$ \\
\hline T9 & $90 \mathrm{a}$ & $90 \mathrm{a}$ & $90 \mathrm{a}$ & $87 \mathrm{a}$ & $83 \mathrm{abc}$ & $72 \mathrm{bc}$ \\
\hline T10 & $87 \mathrm{a}$ & $87 \mathrm{a}$ & $87 \mathrm{ab}$ & $87 \mathrm{a}$ & $87 \mathrm{ab}$ & $76 \mathrm{~b}$ \\
\hline F (trat) & $146,7^{* *}$ & $146,7^{* *}$ & $107,6^{* *}$ & $123,6^{* *}$ & $87,0^{* *}$ & $213,7 * *$ \\
CV (\%) & 6,1 & 6,1 & 7,0 & 6,6 & 7,8 & 5,2 \\
DMS (Tukey) & 11,0 & 11,0 & 12,8 & 11,8 & 14,0 & 8,7 \\
\hline \multicolumn{7}{|c|}{ M-SOY 8001} \\
\hline T1 & $0 \mathrm{e}$ & $0 \mathrm{e}$ & $0 \mathrm{f}$ & $0 \mathrm{e}$ & $0 \mathrm{e}$ & $0 \mathrm{e}$ \\
\hline T2 & $90 \mathrm{a}$ & $90 \mathrm{a}$ & $90 \mathrm{a}$ & $90 \mathrm{a}$ & $90 \mathrm{a}$ & $90 \mathrm{a}$ \\
\hline T3 & $71 \mathrm{~d}$ & $71 \mathrm{~d}$ & $71 \mathrm{~d}$ & $71 \mathrm{~d}$ & $71 \mathrm{~d}$ & $69 \mathrm{~d}$ \\
\hline T4 & $90 \mathrm{a}$ & $90 \mathrm{a}$ & $90 \mathrm{a}$ & $83 \mathrm{~b}$ & $76 \mathrm{c}$ & $0 \mathrm{e}$ \\
\hline T5 & $82 \mathrm{~b}$ & $82 \mathrm{~b}$ & $82 \mathrm{~b}$ & $78 \mathrm{bc}$ & $81 \mathrm{~b}$ & $76 \mathrm{bc}$ \\
\hline T6 & $77 \mathrm{c}$ & $77 \mathrm{c}$ & $77 \mathrm{c}$ & $77 \mathrm{~cd}$ & $77 \mathrm{bc}$ & $77 \mathrm{bc}$ \\
\hline T7 & $70 \mathrm{~d}$ & $70 \mathrm{~d}$ & $68 \mathrm{e}$ & $74 \mathrm{~cd}$ & $74 \mathrm{~cd}$ & $74 \mathrm{c}$ \\
\hline T8 & $90 \mathrm{a}$ & $90 \mathrm{a}$ & $90 \mathrm{a}$ & $90 \mathrm{a}$ & $77 \mathrm{bc}$ & $0 \mathrm{e}$ \\
\hline T9 & $90 \mathrm{a}$ & $90 \mathrm{a}$ & $90 \mathrm{a}$ & $90 \mathrm{a}$ & $90 \mathrm{a}$ & $79 \mathrm{~b}$ \\
\hline T10 & $90 \mathrm{a}$ & $90 \mathrm{a}$ & $90 \mathrm{a}$ & $90 \mathrm{a}$ & $90 \mathrm{a}$ & $79 \mathrm{~b}$ \\
\hline F (trat) & $6415,7^{* *}$ & $6415,7^{* *}$ & $1385,6^{* *}$ & $431,2^{* *}$ & $1160,9^{* *}$ & $1801,3 * *$ \\
CV (\%) & 0,9 & 0,9 & 1,9 & 3,5 & 2,1 & 3,3 \\
DMS (Tukey) & 1,7 & 1,7 & 3,6 & 6,3 & 3,8 & 4,3 \\
\hline
\end{tabular}

T1 - testemunha sem capina; T2 - testemunha capinada; T3 lactofen; T4 - glyphosate; T5 - lactofen + chlorimuron-ethyl; T6 - chlorimuron-ethyl + imazethapyr; T7 - chlorimuron-ethyl + bentazon; T8 - glyphosate + imazethapyr; T9 - lactofen + chlorimuron-ethyl + imazethapyr; T10 - lactofen + chlorimuronethyl + imazethapyr/haloxyfop-methyl.

Médias seguidas da mesma letra na coluna não diferem significativamente entre si pelo teste de Tukey a $5 \%$ de probabilidade.

Dados transformados em ARC SEN $\sqrt{ } \mathrm{x}$. 
Na pré-colheita, os tratamentos glyphosate isolado e em mistura com imazethapyr resultaram em melhor controle das plantas daninhas (em torno de 90\%), quando comparados aos demais tratamentos químicos.

Para a soja M-SOY 8001, aos 6, 13 e 20 DAA, os tratamentos glyphosate, glyphosate + imazethapyr, lactofen + chlorimuron-ethyl + imazethapyr e lactofen + chlorimuron-ethyl + imazethapyr/haloxyfop-methyl proporcionaram controle das plantas daninhas similar ao da testemunha capinada. Aos 27 DAA, os tratamentos glyphosate + imazethapyr, lactofen + chlorimuron-ethyl + imazethapyr e lactofen + chlorimuron-ethyl + imazethapyr/ haloxyfop-methyl e, aos 37 DAA, os tratamentos lactofen + chlorimuron-ethyl + imazethapyr e lactofen + chlorimuron-ethyl + imazethapyr / haloxyfop-methyl possibilitaram controle semelhante ao da testemunha capinada. $\mathrm{Na}$ pré-colheita, foi evidenciado controle inferior com todos os tratamentos químicos comparados à testemunha capinada, devido ao final do ciclo da soja, quando as plantas se encontravam sem folhas, propiciando a germinação e emergência das plantas daninhas pela exposição do solo à luminosidade, dando condições satisfatórias ao crescimento destas.

No segundo ano, a área experimental foi composta basicamente por Alternanthera tenella (apaga-fogo), Digitaria nuda (capim-colchão), Panicum maximum (capim-colonião), Eleusine indica (capim-pé-de-galinha), Cenchrus echinatus (capim-carrapicho), Amaranthus deflexus e Ipomoea spp. (corda-de-viola), com $72 \%$ de dicotiledôneas e $28 \%$ de monocotiledôneas e predominância de apaga-fogo e capim-colchão.

Verificou-se que para a variedade M-SOY 7908 RR, aos 6 DAA, todos os tratamentos químicos proporcionaram controle das plantas daninhas inferior ao da testemunha capinada (Tabela 5). Nas avaliações realizadas aos 13, 20, 27, 37 DAA e na pré-colheita, apenas os tratamentos com glyphosate isolado e glyphosate associado ao imazethapyr resultaram em controle similar ao da testemunha capinada. A mistura lactofen + chlorimuron-ethyl + imazethapyr/haloxyfop-methyl ocasionou melhor controle dos 20 aos 37 DAA quando comparado ao lactofen, lactofen + chlorimuronethyl, chlorimuron-ethyl + imazethapyr e chlorimuron-ethyl + bentazon, indicando ser a mistura de herbicidas com mecanismos de ação diferentes uma boa estratégia para o controle de plantas daninhas.

Para a M-SOY 8001, dos 6 aos 37 DAA, os tratamentos glyphosate isolado e glyphosate + imazethapyr ocasionaram controle similar ao da testemunha capinada. Os demais tratamentos proporcionaram controle das plantas daninhas inferior ao da testemunha capinada. Isso pode ser explicado pelo maior tempo gasto por esse cultivar no seu desenvolvimento e, consequentemente, no fechamento do dossel, favorecendo o desenvolvimento das plantas daninhas pelo menor sombreamento. Na pré-colheita, os tratamentos lactofen +

Tabela 5 - Nível de controle (\%) de plantas daninhas estimado nas variedades de soja M-SOY 7908 RR e M-SOY $8001 \mathrm{em}$ relação aos dias após a aplicação dos tratamentos no ano agrícola 2007/2008. Jaboticabal-SP, 2008

\begin{tabular}{|l|c|c|c|c|c|c|}
\hline Tratamento & 6 DAA & 13 DAA & 20 DAA & 27 DAA & 37 DAA & $\begin{array}{c}\text { Pré- } \\
\text { colheita }\end{array}$ \\
\hline \multicolumn{7}{|c|}{ M-SOY 7908 RR } \\
\hline T1 & $0 \mathrm{f}$ & $0 \mathrm{~d}$ & $0 \mathrm{e}$ & $0 \mathrm{~d}$ & $0 \mathrm{~d}$ & $0 \mathrm{~d}$ \\
\hline T2 & $90 \mathrm{a}$ & $90 \mathrm{a}$ & $90 \mathrm{a}$ & $90 \mathrm{a}$ & $90 \mathrm{a}$ & $90 \mathrm{a}$ \\
\hline T3 & $38 \mathrm{~cd}$ & $30 \mathrm{c}$ & $10 \mathrm{de}$ & $0 \mathrm{~d}$ & $0 \mathrm{~d}$ & $53 \mathrm{bc}$ \\
\hline T4 & $63 \mathrm{~b}$ & $73 \mathrm{a}$ & $90 \mathrm{a}$ & $90 \mathrm{a}$ & $90 \mathrm{a}$ & $90 \mathrm{a}$ \\
\hline T5 & $36 \mathrm{~cd}$ & $25 \mathrm{c}$ & $31 \mathrm{~cd}$ & $0 \mathrm{~d}$ & $0 \mathrm{~d}$ & $38 \mathrm{c}$ \\
\hline T6 & $32 \mathrm{~d}$ & $39 \mathrm{bc}$ & $39 \mathrm{~cd}$ & $29 \mathrm{c}$ & $29 \mathrm{c}$ & $37 \mathrm{c}$ \\
\hline T7 & $21 \mathrm{e}$ & $34 \mathrm{bc}$ & $16 \mathrm{de}$ & $0 \mathrm{~d}$ & $0 \mathrm{~d}$ & $0 \mathrm{~d}$ \\
\hline T8 & $60 \mathrm{~b}$ & $76 \mathrm{a}$ & $87 \mathrm{a}$ & $90 \mathrm{a}$ & $90 \mathrm{a}$ & $90 \mathrm{a}$ \\
\hline T9 & $41 \mathrm{c}$ & $51 \mathrm{~b}$ & $56 \mathrm{bc}$ & $49 \mathrm{bc}$ & $49 \mathrm{bc}$ & $61 \mathrm{~b}$ \\
\hline T10 & $35 \mathrm{~cd}$ & $49 \mathrm{~b}$ & $73 \mathrm{ab}$ & $70 \mathrm{ab}$ & $70 \mathrm{ab}$ & $66 \mathrm{~b}$ \\
\hline F (trat) & $305,6^{* *}$ & $50,4^{* *}$ & $32,9^{* *}$ & $61,2^{* *}$ & $61,2^{* *}$ & $58,1 * *$ \\
CV (\%) & 6,8 & 16,3 & 24,5 & 24,9 & 24,9 & 16,1 \\
DMS (Tukey) & 6,8 & 18,5 & 29,3 & 25,3 & 25,3 & 20,7 \\
\hline \multicolumn{7}{|c|}{ M-SOY 8001} \\
\hline T1 & $0 \mathrm{~d}$ & $0 \mathrm{c}$ & $0 \mathrm{~d}$ & $0 \mathrm{~d}$ & $0 \mathrm{~d}$ & $0 \mathrm{~d}$ \\
\hline T2 & $90 \mathrm{a}$ & $90 \mathrm{a}$ & $90 \mathrm{a}$ & $90 \mathrm{a}$ & $90 \mathrm{a}$ & $90 \mathrm{a}$ \\
\hline T3 & $30 \mathrm{~b}$ & $5 \mathrm{c}$ & $5 \mathrm{~d}$ & $0 \mathrm{~d}$ & $0 \mathrm{~d}$ & $16 \mathrm{~cd}$ \\
\hline T4 & $70 \mathrm{a}$ & $87 \mathrm{a}$ & $79 \mathrm{a}$ & $74 \mathrm{ab}$ & $69 \mathrm{ab}$ & $0 \mathrm{~d}$ \\
\hline T5 & $22 \mathrm{bc}$ & $16 \mathrm{c}$ & $18 \mathrm{~d}$ & $0 \mathrm{~d}$ & $0 \mathrm{~d}$ & $24 \mathrm{~cd}$ \\
\hline T6 & $37 \mathrm{~b}$ & $43 \mathrm{~b}$ & $49 \mathrm{c}$ & $49 \mathrm{c}$ & $45 \mathrm{bc}$ & $41 \mathrm{bc}$ \\
\hline T7 & $6 \mathrm{~cd}$ & $10 \mathrm{c}$ & $0 \mathrm{~d}$ & $0 \mathrm{~d}$ & $0 \mathrm{~d}$ & $18 \mathrm{~cd}$ \\
\hline T8 & $74 \mathrm{a}$ & $87 \mathrm{a}$ & $78 \mathrm{ab}$ & $71 \mathrm{abc}$ & $63 \mathrm{abc}$ & $0 \mathrm{~d}$ \\
\hline T9 & $42 \mathrm{~b}$ & $51 \mathrm{~b}$ & $57 \mathrm{bc}$ & $60 \mathrm{bc}$ & $64 \mathrm{abc}$ & $61 \mathrm{ab}$ \\
\hline T10 & $36 \mathrm{~b}$ & $48 \mathrm{~b}$ & $49 \mathrm{c}$ & $56 \mathrm{bc}$ & $35 \mathrm{c}$ & $66 \mathrm{ab}$ \\
\hline F (trat) & $43,2^{* *}$ & $49,0^{* *}$ & $60,4 *$ & $51,1 * *$ & $26,6^{* *}$ & $20,6^{* *}$ \\
CV (\%) & 21,9 & 23,1 & 20,9 & 25,2 & 36,6 & 44,1 \\
DMS (Tukey) & 21,7 & 24,5 & 21,6 & 24,5 & 32,5 & 33,9 \\
\hline
\end{tabular}

T1 - testemunha sem capina; T2 - testemunha capinada; T3 lactofen; T4 - glyphosate; T5 - lactofen + chlorimuron-ethyl; T6 - chlorimuron-ethyl + imazethapyr; T7 - chlorimuron-ethyl + bentazon; T8 - glyphosate + imazethapyr; T9 - lactofen + chlorimuron-ethyl + imazethapyr; T10 - lactofen + chlorimuronethyl + imazethapyr/haloxyfop-methyl.

Médias seguidas da mesma letra na coluna não diferem significativamente entre si pelo teste de Tukey a $5 \%$ de probabilidade.

Dados transformados em ARC SEN $\sqrt{ } \mathrm{x}$. 
chlorimuron-ethyl + imazethapyr e lactofen + chlorimuron-ethyl + imazethapyr/haloxyfopmethyl resultaram em melhor controle quando comparados aos demais tratamentos químicos.

No primeiro ano, para a variedade M-SOY 7908 RR, observou-se que a aplicação dos produtos influenciou significativamente a matéria seca das plantas daninhas (Tabela 6) na pré-colheita; a maior massa foi observada na testemunha sem capina, e os efeitos dos tratamentos químicos não diferiram estatisticamente entre si. Para a M-SOY 8001, com exceção de glyphosate e glyphosate + imazethapyr, que apresentaram maiores valores de matéria seca das plantas daninhas, os demais tratamentos químicos não diferiram estatisticamente da testemunha capinada.

No segundo ano (Tabela 6), para a variedade M-SOY 7908 RR, os tratamentos glyphosate, glyphosate + imazethapyr e testemunha capinada proporcionaram valores nulos, os quais diferiram estatisticamente dos tratamentos lactofen + chlorimuron-ethyl, chlorimuronethyl + bentazon e testemunha sem capina, que resultaram em maiores valores de massa. Quanto à M-SOY 8001, o tratamento chlorimuron-ethyl + bentazon resultou em maior matéria seca das plantas daninhas, porém não diferiu estatisticamente dos demais tratamentos químicos e da testemunha sem capina.

Analisando os dados de matéria seca, observaram-se maiores valores no segundo ano agrícola para os dois cultivares estudados. Isso pode ter ocorrido devido à alta infestação de plantas daninhas, o que não aconteceu na área em que foi desenvolvido o experimento no primeiro ano.

\section{Componentes de produção e produtividade da cultura}

No primeiro ano, não houve efeito significativo de tratamentos na altura final (Tabela 7) das plantas da variedade M-SOY 7908 RR. Para a M-SOY 8001, foi constatada redução de 15\% na altura das plantas tratadas com lactofen + chlorimuron-ethyl + imazethapyr, comparadas às da testemunha sem capina, não diferindo dos outros tratamentos. Tendência semelhante foi relatada por Souza et al. (2002), que,
Tabela 6 - Massa seca $\left(\mathrm{g} \mathrm{m}^{-2}\right)$ das plantas daninhas estimada nas variedades de soja M-SOY 7908 RR e M-SOY 8001 em relação aos dias após a aplicação dos tratamentos nos anos agrícolas 2006/2007 e 2007/2008. Jaboticabal-SP, 2008

\begin{tabular}{|c|c|c|}
\hline Tratamento & M-SOY 7908 RR & M-SOY 8001 \\
\hline \multicolumn{3}{|c|}{$2006 / 2007$} \\
\hline $\mathrm{T} 1$ & $418,29 \mathrm{a}$ & 229,13 bc \\
\hline $\mathrm{T} 2$ & $0,00 \mathrm{~b}$ & $0,00 \mathrm{c}$ \\
\hline T3 & $92,17 \mathrm{~b}$ & $57,08 \mathrm{c}$ \\
\hline $\mathrm{T} 4$ & $0,00 \mathrm{~b}$ & $605,30 \mathrm{a}$ \\
\hline T5 & $126,90 \mathrm{~b}$ & $23,97 \mathrm{c}$ \\
\hline T6 & $105,29 \mathrm{~b}$ & $39,33 \mathrm{c}$ \\
\hline $\mathrm{T} 7$ & $124,14 \mathrm{~b}$ & $99,54 \mathrm{c}$ \\
\hline $\mathrm{T} 8$ & $0,00 \mathrm{~b}$ & $451,17 \mathrm{ab}$ \\
\hline T9 & $51,36 \mathrm{~b}$ & $22,50 \mathrm{c}$ \\
\hline T10 & $49,60 \mathrm{~b}$ & $10,77 \mathrm{c}$ \\
\hline F (trat) & $9,46 * *$ & $9,88^{*}$ \\
\hline CV $(\%)$ & 83,06 & 87,36 \\
\hline DMS (Tukey) & 195,51 & 326,96 \\
\hline \multicolumn{3}{|c|}{$2007 / 2008$} \\
\hline $\mathrm{T} 1$ & $794,00 \mathrm{ab}$ & $1001,79 \mathrm{a}$ \\
\hline $\mathrm{T} 2$ & $0,00 \mathrm{~d}$ & $0,00 \mathrm{~b}$ \\
\hline T3 & $283,34 \mathrm{~cd}$ & $781,84 \mathrm{ab}$ \\
\hline $\mathrm{T} 4$ & $0,00 \mathrm{~d}$ & $745,29 \mathrm{ab}$ \\
\hline T5 & $816,92 \mathrm{a}$ & $427,22 \mathrm{ab}$ \\
\hline T6 & $298,26 \mathrm{bcd}$ & $701,12 \mathrm{ab}$ \\
\hline $\mathrm{T} 7$ & $722,30 \mathrm{abc}$ & $993,39 \mathrm{a}$ \\
\hline $\mathrm{T} 8$ & $0,00 \mathrm{~d}$ & $692,23 \mathrm{ab}$ \\
\hline T9 & $172,86 \mathrm{~d}$ & $251,24 \mathrm{ab}$ \\
\hline T10 & $105,61 \mathrm{~d}$ & $160,21 \mathrm{ab}$ \\
\hline F (trat) & $10,57 * *$ & $3,07 *$ \\
\hline CV (\%) & 64,54 & 68,98 \\
\hline DMS (Tukey) & 501,24 & 965,48 \\
\hline
\end{tabular}

T1 - testemunha sem capina; T2 - testemunha capinada; T3 lactofen; T4 - glyphosate; T5 - lactofen + chlorimuron-ethyl; T6 - chlorimuron-ethyl + imazethapyr; T7 - chlorimuron-ethyl + bentazon; T8 - glyphosate + imazethapyr; T9 - lactofen + chlorimuron-ethyl + imazethapyr; T10 - lactofen + chlorimuronethyl + imazethapyr/haloxyfop-methyl.

Médias seguidas da mesma letra na coluna não diferem significativamente entre si pelo teste de Tukey a $5 \%$ de probabilidade

estudando a seletividade das combinações do herbicida lactofen na cultura da soja BR-37, mencionaram reduções na altura das plantas de 10,50 a $5,75 \%$ aos 20 e 40 DAA do herbicida, respectivamente. Esses autores constataram que o lactofen combinado ao chlorimuron-ethyl e ao imazethapyr a $75 \%$ da dose comercial ocasionaram reduções na altura de plantas de 11 e $10 \%$, respectivamente, aos 20 DAA.

Analisando as variáveis altura de inserção da primeira vagem, número de vagens (Tabela 7) e massa de 100 grãos (Tabela 8), não houve 
Tabela 7 - Altura de plantas, altura de inserção da primeira vagem e número de vagens estimadas em plantas das variedades de soja M-SOY 7908 RR e M-SOY 8001 em resposta aos tratamentos experimentais no ano agrícola 2006/ 2007. Jaboticabal-SP, 2008

\begin{tabular}{|l|c|c|c|}
\hline Tratamento & $\begin{array}{c}\text { Altura das } \\
\text { plantas (cm) }\end{array}$ & $\begin{array}{c}\text { Altura de } \\
\text { inserção da } \\
\text { primeira } \\
\text { vagem }\end{array}$ & $\begin{array}{c}\text { Número de } \\
\text { vagens } 1 /\end{array}$ \\
\hline \multicolumn{4}{|c|}{ M-SOY 7908 RR } \\
\hline T1 & 78,88 & 23,35 & 5,28 \\
\hline T2 & 79,47 & 18,91 & 5,63 \\
\hline T3 & 77,13 & 23,89 & 5,89 \\
\hline T4 & 79,41 & 20,40 & 5,82 \\
\hline T5 & 74,27 & 23,27 & 5,24 \\
\hline T6 & 78,25 & 22,27 & 5,24 \\
\hline T7 & 78,55 & 20,70 & 4,81 \\
\hline T8 & 74,99 & 21,80 & 5,19 \\
\hline T9 & 76,42 & 21,21 & 5,61 \\
\hline T10 & 76,15 & 23,20 & 5,26 \\
\hline F (trat) & $0,46 \mathrm{~ns}$ & $0,89 \mathrm{~ns}$ & $1,34 \mathrm{~ns}$ \\
CV (\%) & 7,06 & 15,44 & 10,61 \\
DMS (Tukey) & 13,27 & 8,22 & 1,39 \\
\hline \multicolumn{4}{|c|}{ M-SOY 8001} \\
\hline T1 & $79,29 \mathrm{a}$ & $15,30 \mathrm{a}$ & $6,50 \mathrm{a}$ \\
\hline T2 & $75,36 \mathrm{ab}$ & $15,65 \mathrm{a}$ & $6,68 \mathrm{a}$ \\
\hline T3 & $77,32 \mathrm{ab}$ & $17,82 \mathrm{a}$ & $6,32 \mathrm{a}$ \\
\hline T4 & $0,00 \mathrm{c}$ & $0,00 \mathrm{~b}$ & $0,00 \mathrm{~b}$ \\
\hline T5 & $74,62 \mathrm{ab}$ & $16,10 \mathrm{a}$ & $6,86 \mathrm{a}$ \\
\hline T6 & $72,31 \mathrm{ab}$ & $16,95 \mathrm{a}$ & $6,00 \mathrm{a}$ \\
\hline T7 & $77,17 \mathrm{ab}$ & $16,82 \mathrm{a}$ & $6,18 \mathrm{a}$ \\
\hline T8 & $0,00 \mathrm{c}$ & $0,00 \mathrm{~b}$ & $0,00 \mathrm{~b}$ \\
\hline T9 & $67,02 \mathrm{~b}$ & $17,72 \mathrm{a}$ & $6,52 \mathrm{a}$ \\
\hline T10 & $71,23 \mathrm{ab}$ & $15,17 \mathrm{a}$ & $6,34 \mathrm{a}$ \\
\hline F (trat) & $187,26^{* *}$ & $39,42 * *$ & $123,54 * *$ \\
CV (\%) & 7,75 & 16,93 & 9,52 \\
DMS (Tukey) & 11,20 & 5,41 & 1,19 \\
\hline
\end{tabular}

T1 - testemunha sem capina; T2 - testemunha capinada; T3 lactofen; T4 - glyphosate; T5 - lactofen + chlorimuron-ethyl; T6 - chlorimuron-ethyl + imazethapyr; T7 - chlorimuron-ethyl + bentazon; T8 - glyphosate + imazethapyr; T9 - lactofen + chlorimuron-ethyl + imazethapyr; T10 - lactofen + chlorimuronethyl + imazethapyr/haloxyfop-methyl.

Médias seguidas da mesma letra na coluna não diferem significativamente entre si pelo teste de Tukey a $5 \%$ de probabilidade.

Dados transformados para $\bigvee_{\mathbf{n}}$.

efeito dos tratamentos nas plantas dos dois cultivares de soja. Barros et al. (2000), em ensaio com misturas de lactofen com oxasulfuron, cloransulam-methyl e chlorimuron-ethyl, também não constataram diferença significativa entre a altura de planta e de inserção da primeira vagem em função dos tratamentos aplicados.

No tocante à produtividade de grãos da variedade M-SOY $7908 \mathrm{RR}$ (Tabela 8), apenas as plantas pulverizadas com lactofen, chlorimuron-ethyl + bentazon e a testemunha sem capina apresentaram valores inferiores aos da testemunha capinada. No entanto, Wichert \& Talbert (1993), testando diferentes doses de lactofen $\left(0,22\right.$ e $0,44 \mathrm{~kg}$ i.a. ha- $\left.{ }^{-1}\right)$ e estádios de desenvolvimento da soja $\left(\mathrm{V}_{1}\right.$ e $\left.\mathrm{V}_{2}\right)$, não observaram diferenças significativas em relação à produtividade.

Em relação a M-SOY 8001, com exceção dos tratamentos glyphosate isolado e associado ao imazethapyr, que causaram a morte das plantas, a produtividade de grãos não foi influenciada pelos tratamentos químicos.

Tabela 8 - Massa de 100 grãos e produtividade das variedades de soja M-SOY 7908 RR e M-SOY 8001 em resposta aos tratamentos experimentais no ano agrícola 2006/2007. Jaboticabal-SP, 2008

\begin{tabular}{|c|c|c|}
\hline Tratamento & $\begin{array}{l}\text { Massa de } 100 \text { grãos } \\
(\mathrm{g})\end{array}$ & $\begin{array}{c}\text { Produtividade } \\
\left(\mathrm{kg} \mathrm{ha}^{-1}\right)\end{array}$ \\
\hline \multicolumn{3}{|c|}{ M-SOY 7908 RR } \\
\hline $\mathrm{T} 1$ & 18,41 & $2414 \mathrm{c}$ \\
\hline $\mathrm{T} 2$ & 19,15 & $3015 \mathrm{a}$ \\
\hline $\mathrm{T} 3$ & 18,45 & $2408 \mathrm{c}$ \\
\hline $\mathrm{T} 4$ & 19,00 & $2711 \mathrm{abc}$ \\
\hline T5 & 18,26 & $2796 \mathrm{abc}$ \\
\hline T6 & 19,04 & $2826 \mathrm{abc}$ \\
\hline $\mathrm{T} 7$ & 19,03 & $2535 \mathrm{bc}$ \\
\hline $\mathrm{T} 8$ & 19,03 & $2933 \mathrm{ab}$ \\
\hline T9 & 18,46 & $2759 \mathrm{abc}$ \\
\hline $\mathrm{T} 10$ & 18,63 & $2716 \mathrm{abc}$ \\
\hline F (trat) & $0,51 \mathrm{~ns}$ & $5,04 * *$ \\
\hline $\mathrm{CV}(\%)$ & 5,00 & 6,71 \\
\hline DMS (Tukey) & 2,28 & 442,53 \\
\hline \multicolumn{3}{|c|}{ M-SOY 8001} \\
\hline $\mathrm{T} 1$ & $14,05 \mathrm{a}$ & $2761 \mathrm{a}$ \\
\hline $\mathrm{T} 2$ & $13,79 a$ & $3090 \mathrm{a}$ \\
\hline $\mathrm{T} 3$ & $13,81 \mathrm{a}$ & $3288 \mathrm{a}$ \\
\hline $\mathrm{T} 4$ & $0 \mathrm{~b}$ & $0 \mathrm{~b}$ \\
\hline T5 & $13,83 \mathrm{a}$ & $3220 \mathrm{a}$ \\
\hline T6 & $13,46 \mathrm{a}$ & $3190 \mathrm{a}$ \\
\hline $\mathrm{T} 7$ & $14,03 \mathrm{a}$ & $3248 \mathrm{a}$ \\
\hline $\mathrm{T} 8$ & $0,00 \mathrm{~b}$ & $0 \mathrm{~b}$ \\
\hline T9 & $14,20 \mathrm{a}$ & $3149 a$ \\
\hline $\mathrm{T} 10$ & $13,20 \mathrm{a}$ & $3319 a$ \\
\hline $\mathrm{F}$ (trat) & $227,36^{* *}$ & $121,80^{* *}$ \\
\hline $\mathrm{CV}(\%)$ & 7,00 & 9,62 \\
\hline DMS (Tukey) & 1,87 & 590,90 \\
\hline
\end{tabular}

T1 - testemunha sem capina; T2 - testemunha capinada; T3 lactofen; T4 - glyphosate; T5 - lactofen + chlorimuron-ethyl; T6 - chlorimuron-ethyl + imazethapyr; T7 - chlorimuron-ethyl + bentazon; T8 - glyphosate + imazethapyr; T9 - lactofen + chlorimuron-ethyl + imazethapyr; T10 - lactofen + chlorimuronethyl + imazethapyr/haloxyfop-methyl.

Médias seguidas da mesma letra na coluna não diferem significativamente entre si pelo teste de Tukey a $5 \%$ de probabilidade. 
Os resultados do segundo ano para os componentes de produção da soja mostraram que os tratamentos químicos influenciaram a altura final das plantas (Tabela 9) da variedade M-SOY 7908 RR. As plantas tratadas com chlorimuron-ethyl + imazethapyr, lactofen + chlorimuron-ethyl + imazethapyr e lactofen + chlorimuron-ethyl + imazethapyr/haloxyfopmethyl apresentaram redução de 18, 11 e 16\% em altura, respectivamente, comparadas às da testemunha sem capina. Procópio et al. (2007) relataram que a associação de imazethapyr ao glyphosate reduziu a altura das plantas de soja transgênica, e, nesta pesquisa, a associação de imazethapyr a lactofen, chlorimuronethyl e haloxyfop-methyl mostrou efeito semelhante. Krausz \& Young (2001b) constataram que a aplicação do herbicida imazethapyr reduziu a altura da soja geneticamente modificada tolerante ao glyphosate.

Verificou-se para a variedade M-SOY 8001 redução de 22, 21 e 27\% na altura das plantas (Tabela 9) tratadas com chlorimuron-ethyl + imazethapyr, lactofen + chlorimuron-ethyl + imazethapyr e lactofen + chlorimuron-ethyl + imazethapyr/haloxyfop-methyl, respectivamente, em relação à testemunha sem capina. Em geral, observou-se que o cultivar M-SOY 7908 RR apresentou os maiores valores de altura de plantas comparados aos da variedade convencional, independentemente dos tratamentos utilizados, o que corrobora o melhor fechamento de entrelinhas constatado no cultivo dessa variedade.

Não foi constatada interferência dos tratamentos nos dois cultivares para as variáveis altura de inserção da primeira vagem, número de vagens (Tabela 9) e massa de 100 grãos (Tabela 10), com exceção do número de vagens na variedade M-SOY 8001 tratada com lactofen + chlorimuron-ethyl, que apresentou redução de $21 \%$ no número de vagens comparado ao da testemunha capinada. Esse resultado não pode ser atribuído às características genéticas do cultivar, e sim à interferência das plantas daninhas, visto que no primeiro ano agrícola não foi evidenciado o mesmo comportamento do cultivar. Lamego et al. (2004) observaram redução do número de vagens por planta quando os cultivares de soja foram submetidos à interferência da comunidade infestante.
Quanto à produtividade de grãos (Tabela 10) das plantas da M-SOY 7908 RR, não foram verificadas diferenças significativas entre os tratamentos químicos nem entre eles e as testemunhas, havendo diferença significativa apenas entre as testemunhas, demonstrando assim que a interferência causada pela presença das plantas daninhas não controladas ou parcialmente controladas pelos tratamentos herbicidas não foi suficiente para afetar essa característica. Esses resultados

Tabela 9 - Altura de plantas, altura de inserção da primeira vagem e número de vagens estimadas em plantas das variedades de soja M-SOY 7908 RR e M-SOY $8001 \mathrm{em}$ resposta aos tratamentos experimentais no ano agrícola 2007/ 2008. Jaboticabal-SP, 2008

\begin{tabular}{|l|c|c|c|}
\hline Tratamento & $\begin{array}{c}\text { Altura das } \\
\text { plantas (cm) }\end{array}$ & $\begin{array}{c}\text { Altura de } \\
\text { inserção da } \\
\text { primeira } \\
\text { vagem (cm) }\end{array}$ & $\begin{array}{c}\text { Número de } \\
\text { vagens }{ }^{1}\end{array}$ \\
\hline \multicolumn{4}{|c|}{ M-SOY 7908 RR } \\
\hline T1 & $93,03 \mathrm{ab}$ & 28,94 & 6,16 \\
\hline T2 & $92,68 \mathrm{abc}$ & 28,95 & 6,02 \\
\hline T3 & $90,46 \mathrm{abc}$ & 27,89 & 6,29 \\
\hline T4 & $90,79 \mathrm{abc}$ & 28,61 & 6,37 \\
\hline T5 & $86,83 \mathrm{abcd}$ & 29,56 & 6,36 \\
\hline T6 & $76,63 \mathrm{e}$ & 25,25 & 6,30 \\
\hline T7 & $95,29 \mathrm{a}$ & 29,13 & 6,55 \\
\hline T8 & $82,93 \mathrm{bcde}$ & 26,30 & 6,11 \\
\hline T9 & $82,71 \mathrm{cde}$ & 28,09 & 6,77 \\
\hline T10 & $77,70 \mathrm{de}$ & 27,73 & 6,46 \\
\hline F (trat) & $10,02 * *$ & $0,58 \mathrm{~ns}$ & $0,79 \mathrm{~ns}$ \\
CV (\%) & 4,80 & 12,63 & 7,76 \\
DMS (Tukey) & 10,15 & 8,61 & 1,19 \\
\hline \multicolumn{4}{|c|}{ M-SOY 8001} \\
\hline T1 & $87,35 \mathrm{a}$ & $16,68 \mathrm{a}$ & $6,88 \mathrm{ab}$ \\
\hline T2 & $79,08 \mathrm{ab}$ & $17,68 \mathrm{a}$ & $8,17 \mathrm{a}$ \\
\hline T3 & $74,40 \mathrm{abc}$ & $17,63 \mathrm{a}$ & $7,05 \mathrm{ab}$ \\
\hline T4 & $0,00 \mathrm{~d}$ & $0,00 \mathrm{~b}$ & $0,00 \mathrm{c}$ \\
\hline T5 & $77,43 \mathrm{ab}$ & $18,03 \mathrm{a}$ & $6,42 \mathrm{~b}$ \\
\hline T6 & $67,70 \mathrm{bc}$ & $16,88 \mathrm{a}$ & $7,42 \mathrm{ab}$ \\
\hline T7 & $82,30 \mathrm{a}$ & $17,58 \mathrm{a}$ & $6,92 \mathrm{ab}$ \\
\hline T8 & $0,00 \mathrm{~d}$ & $0,00 \mathrm{~b}$ & $0,00 \mathrm{c}$ \\
\hline T9 & $68,48 \mathrm{bc}$ & $17,15 \mathrm{a}$ & $7,12 \mathrm{ab}$ \\
\hline T10 & $63,18 \mathrm{c}$ & $16,48 \mathrm{a}$ & $7,57 \mathrm{ab}$ \\
\hline F (trat) & $146,67 * *$ & $67,95^{* *}$ & $86,48^{* *}$ \\
CV (\%) & 8,93 & 12,82 & 11,47 \\
DMS (Tukey) & 13,02 & 4,30 & 1,60 \\
\hline
\end{tabular}

T1 - testemunha sem capina; T2 - testemunha capinada; T3 lactofen; T4 - glyphosate; T5 - lactofen + chlorimuron-ethyl; T6 - chlorimuron-ethyl + imazethapyr; T7 - chlorimuron-ethyl + bentazon; T8 - glyphosate + imazethapyr; T9 - lactofen + chlorimuron-ethyl + imazethapyr; T10 - lactofen + chlorimuronethyl + imazethapyr/haloxyfop-methyl.

Médias seguidas da mesma letra na coluna não diferem significativamente entre si pelo teste de Tukey a $5 \%$ de probabilidade.

Dados transformados para $\bigvee_{\mathbf{n}}$ 
também podem ser explicados pelo rápido e vigoroso crescimento apresentado pelo cultivar, que ocasionou o sombreamento do solo, dificultando o crescimento das plantas daninhas tanto nas parcelas tratadas com herbicidas quanto nas parcelas sem capina.

Em relação à variedade M-SOY 8001, exceto para glyphosate e glyphosate + imazethapyr, que ocasionaram a morte das plantas, os tratamentos chlorimuron-ethyl + bentazon e testemunha sem capina registraram os menores niveis de produtividade, comparados aos da testemunha capinada, que resultou nos maiores valores.

Tabela 10 - Massa de 100 grãos e produtividade das variedades de soja M-SOY 7908 RR e M-SOY 8001 em resposta aos tratamentos experimentais no ano agrícola 2007/2008. Jaboticabal-SP, 2008

\begin{tabular}{|c|c|c|}
\hline Tratamento & $\begin{array}{c}\text { Massa de } 100 \text { grãos } \\
(\mathrm{g})\end{array}$ & $\begin{array}{c}\text { Produtividade } \\
\left(\mathrm{kg} \mathrm{ha}^{-1}\right)\end{array}$ \\
\hline \multicolumn{3}{|c|}{ M-SOY 7908 RR } \\
\hline T1 & 19,65 & $2535 \mathrm{~b}$ \\
\hline $\mathrm{T} 2$ & 20,01 & $3376 \mathrm{a}$ \\
\hline T3 & 19,28 & $3186 \mathrm{ab}$ \\
\hline $\mathrm{T} 4$ & 20,09 & $3109 \mathrm{ab}$ \\
\hline T5 & 19,67 & $2757 \mathrm{ab}$ \\
\hline T6 & 19,22 & $3213 \mathrm{ab}$ \\
\hline $\mathrm{T} 7$ & 19,92 & $2897 \mathrm{ab}$ \\
\hline T8 & 19,67 & $3059 \mathrm{ab}$ \\
\hline T9 & 19,17 & $3150 \mathrm{ab}$ \\
\hline $\mathrm{T} 10$ & 19,52 & $3058 \mathrm{ab}$ \\
\hline F (trat) & $1,66 \mathrm{~ns}$ & $2,54^{*}$ \\
\hline $\mathrm{CV}(\%)$ & 2,57 & 10,10 \\
\hline DMS (Tukey) & 1,22 & 745,49 \\
\hline \multicolumn{3}{|c|}{ M-SOY 8001} \\
\hline T1 & $12,33 \mathrm{a}$ & $1995 \mathrm{~b}$ \\
\hline $\mathrm{T} 2$ & $12,67 \mathrm{a}$ & $3141 \mathrm{a}$ \\
\hline $\mathrm{T} 3$ & $12,20 \mathrm{a}$ & $2342 \mathrm{ab}$ \\
\hline $\mathrm{T} 4$ & $0 \mathrm{~b}$ & $0 \mathrm{c}$ \\
\hline $\mathrm{T} 5$ & $12,67 \mathrm{a}$ & $2311 \mathrm{ab}$ \\
\hline T6 & $11,89 \mathrm{a}$ & $2373 \mathrm{ab}$ \\
\hline $\mathrm{T} 7$ & $12,50 \mathrm{a}$ & $2068 \mathrm{~b}$ \\
\hline $\mathrm{T} 8$ & $0 \mathrm{~b}$ & $0 \mathrm{c}$ \\
\hline T9 & $12,09 \mathrm{a}$ & $2686 \mathrm{ab}$ \\
\hline T10 & $12,42 \mathrm{a}$ & $2791 \mathrm{ab}$ \\
\hline $\mathrm{F}($ trat $)$ & $304,27^{* *}$ & $33,22 * *$ \\
\hline $\mathrm{CV}(\%)$ & 6,05 & 19,24 \\
\hline DMS (Tukey) & 1,45 & 922,16 \\
\hline
\end{tabular}

T1 - testemunha sem capina; T2 - testemunha capinada; T3 lactofen; T4 - glyphosate; T5 - lactofen + chlorimuron-ethyl; T6 - chlorimuron-ethyl + imazethapyr; T7 - chlorimuron-ethyl + bentazon; T8 - glyphosate + imazethapyr; T9 - lactofen + chlorimuron-ethyl + imazethapyr; T10 - lactofen + chlorimuronethyl + imazethapyr/haloxyfop-methyl.

Médias seguidas da mesma letra na coluna não diferem significativamente entre si pelo teste de Tukey a $5 \%$ de probabilidade.
Com base nos resultados, pode-se concluir que os herbicidas comportaram-se de maneira diferente nas duas áreas de estudo. De maneira geral, foi evidenciada significativa tolerância da soja aos herbicidas aplicados, com exceção dos tratamentos com glyphosate na soja M-SOY 8001. Na condição de baixa infestação de plantas daninhas, o herbicida lactofen isolado e a mistura chlorimuron-ethyl + bentazon afetaram a produtividade da soja transgênica. Não houve efeito significativo dos tratamentos químicos sobre os componentes de produção. Na área com maior infestação de plantas daninhas, o pior tratamento químico foi chlorimuron-ethyl + bentazon, que reduziu a produtividade da soja convencional; os tratamentos chlorimuron-ethyl + imazethapyr, lactofen + chlorimuron-ethyl + imazethapyr e chlorimuron-ethyl + imazethapyr/haloxyfopmethyl influenciaram de forma negativa o crescimento da cultura, mas não afetaram a produtividade. A aplicação isolada de glyphosate em mistura com imazethapyr apresentou melhor controle das plantas daninhas.

\section{AGRADECIMENTOS}

À Universidade Estadual do Maranhão (UEMA), pela concessão de bolsa de doutorado à primeira autora.

\section{LITERATURA CITADA}

ANDRIOLI, I.; CENTURION, J. F. Levantamento detalhado dos solos da Faculdade de Ciências Agrárias e Veterinárias de Jaboticabal. In: CONGRESSO BRASILEIRO DE CIÊNCIA DO SOLO, 27., 1999, Brasília. Anais... Brasília: Sociedade Brasileira de Ciência do Solo, 1999. p. 32. CD-ROM.

BARROS, C. A.; UEDA, A.; SCHUMM, K. C. Eficiência e seletividade do lactofen em mistura com outros latifolicidas no controle de plantas daninhas na cultura da soja. R. Bras. Herbic., v. 1, n. 1, p. 79-84, 2000.

COOPERATIVA DOS AGRICULTORES DA REGIÃO DE ORLÂNDIA - CAROL. A soja na safra atual 2006/2007. Disponível em: <www.carol.com.br>. Acesso em: 12 nov. 2007.

CHRISTOFFOLETI, P. J.; VICTORIA FILHO, R.; SILVA, C. B. Resistência de plantas daninhas aos herbicidas.

Planta Daninha, v. 12, n. 1, p. 13-20, 1994. 
COMPANHIA NACIONAL DE ABASTECIMENTO CONAB. Acompanhamento da safra brasileira de grãos 2007/2008: décimo segundo levantamento, setembro, 2008. Disponível em: <http//www.conab.gov.br>. Acesso em: 3 out. 2008.

CONSTANTIN, J.; OLIVEIRA Jr., R. S.; MACIEL, C. D. G. Avaliação de misturas em tanque de imazethapyr com outros herbicidas para o controle de Bidens pilosa e Euphorbia heterophylla em soja. R. Bras. Herbic., v. 1, n. 1, p. 73-78, 2000.

EUROPEAN WEED RESEARCH COUNCIL - EWRC. Report of $3^{\text {rd }}$ and 4rd meetings of EWRC. Citee of methods in weed research. Weed Res., v. 4, p. 88, 1964

FOLONI, L. L. et al. Aplicação de glifosato em pósemergência, em soja transgênica cultivada no cerrado. R. Bras. Herbic., v. 3, n. 1, p. 47-58, 2005.

KRAUSZ, R. F.; YOUNG, B. G. Response of glyphosateresistant soybean (Glycine max) to trimetylsulfonium and isopropylamine salts of glyphosate. Weed Technol., v. 15, n. 4, p. $745-749,2001 \mathrm{a}$

KRAUSZ, R. F.; YOUNG, B. G. Response of double-crop glyphosate-resistant soybean (Glycine max) to broadleaf herbicides. Weed Technol., v. 15, n. 2, p. 300-305, 2001b.

LAMEGO, F. P. et al. Tolerância à interferência de plantas competidoras e habilidade de supressão por genótipos de soja - II. Resposta de variáveis de produtividade.

Planta Daninha, v. 22, n. 4, p. 491-498, 2004

MELHORANÇA, A. L.; PEREIRA, F. A. R. Eficiência do herbicida lactofen no controle de Euphorbia heterophylla resistente aos herbicidas inibidores da enzima acetolactato sintase (ALS). R. Bras. Herbic., v. 1, n. 1, p. 53-56, 2000.
MONQUERO, P. A.; CHRISTOFFOLETI, P. J.; SANTOS, C. T. D. Glyphosate em mistura com herbicidas alternativos para o manejo de plantas daninhas. Planta Daninha, v. 19, n. 3 , p. $375-380,2001$.

PETTER, F. A. et al. Manejo de herbicidas na cultura da soja Roundup Ready. Planta Daninha, v. 25, n. 3, p. 557-566, 2007.

PITELLI, R. A. Interferência de plantas daninhas em culturas agrícolas. Inf. Agropec., v. 11, p. 16-27, 1985.

PROCÓPIO, S. O. et al. Utilização de chlorimuron-ethyl e imazethapyr na cultura da soja Roundup Ready

Planta Daninha, v. 25, n. 2, p. 365-373, 2007.

RITCHIE, S.W. et al. How a soybean plant develops. Ames: Yowa State University of Science and Technology, 1977. 20 p. (Special Report, 53).

SOUZA, R. T. et al. Seletividade de combinações de herbicidas latifolicidas com lactofen para a cultura da soja. Sci. Agríc., v. 59, n. 1, p. 99-106, 2002.

VARGAS, L. et al. Resistência de plantas daninhas a herbicidas. Viçosa, MG: Universidade Federal de Viçosa, 1999. $131 \mathrm{p}$.

VIDRINE, P. R.; GRIFFIN, J. L.; BLOUIN, D. C. Evaluation of reduced rates of glyphosate and chlorimuron in glyphosateresistant soybean (Glycine max). Weed Technol., v. 16, n. 4, p. $731-736,2002$.

WICHERT, R. A.; TALBERT, R. E. Soybean [Glycine max (L.) response to lactofen. Weed Sci., v. 41, n. 1, p. 23-26, 1993. 